\title{
Complete endoscopic resection of a pituitary stalk epidermoid cyst using a combined infrasellar interpituitary and suprasellar endonasal approach: case report
}

\author{
Ana C. I. Nakassa, MD, ${ }^{1}$ Joseph D. Chabot, DO, ${ }^{2}$ Carl H. Snyderman, MD, MBA, ${ }^{1}$ Eric W. Wang, MD, ${ }^{1}$ \\ Paul A. Gardner, MD,'1 and Juan C. Fernandez-Miranda, MD' \\ 'Department of Neurological Surgery, University of Pittsburgh School of Medicine, Pittsburgh, Pennsylvania; and ${ }^{2}$ Department of \\ Neurosciences, St. Cloud Hospital, St. Cloud, Minnesota \\ Intracranial epidermoid cysts are benign lesions of epithelial origin that most frequently present with symptoms of mass \\ effect. Although they are often associated with a high rate of residual tumor and recurrence, maximal safe resection usu- \\ ally leads to good outcomes. The authors report a complete resection of an uncommon pituitary stalk epidermoid cyst \\ with intrasellar extension using a combined suprasellar and infrasellar interpituitary, endoscopic endonasal transsphenoi- \\ dal approach. The patient, a 54-year-old woman, presented with headache, visual disturbance, and diabetes insipidus. \\ Postoperatively, she reported improvement in her visual symptoms and well-controlled diabetes insipidus using $0.1 \mathrm{mg}$ \\ of desmopressin at bedtime and normal anterior pituitary gland function. One year later, she continues to receive the \\ same dosage of desmopressin and is also taking $50 \mathrm{mcg}$ of levothyroxine daily after developing primary hypothyroidism \\ unrelated to the surgical procedure. A combined infrasellar interpituitary and suprasellar approach to this rare location \\ for an epidermoid cyst can lead to a safe and complete resection with good clinical outcomes. \\ https://thejns.org/doi/abs/10.3171/2016.11.JNS161605
}

KEY WORDS epidermoid cyst; pituitary stalk; endoscopic endonasal; sellar tumor; suprasellar tumor; pituitary surgery

$\mathrm{E}$ PIDERMOID cysts are lesions developed from neuroectodermal epithelial cells. They are a benign pathology, rarely undergoing malignant transformation, ${ }^{16}$ characterized by a white, pearly capsule filled with cholesterol crystals and lamellated keratin debris content. ${ }^{17,18}$ An intracranial location for these lesions is uncommon, accounting for $1.5 \%$ of all epidermoid tumors and $0.3 \%-1.8 \%$ of all intracranial tumors., ${ }^{71}$

In this paper, we report the complete and safe removal of an epidermoid cyst arising from the pituitary stalk using a combined infrasellar interpituitary and suprasellar endoscopic endonasal transsphenoidal approach. This lesion was particularly challenging because of its location between the anterior pituitary gland and neurohypophysis with suprasellar extension within the pituitary stalk, requiring modification of a standard transsellar approach for optimal access. A review of the literature shows that this is one of only a few such lesions reported in this location, and the first removed using this surgical method. The endoscopic endonasal approach (EEA) allows maximal safe total resection without the need for a craniotomy, thereby decreasing the chance of recurrence and malignant transformation in this rare pathology.

\section{Case Report}

History and Examination

A 54-year-old woman presented as an outpatient complaining of an acute onset of blurry vision with progressive deterioration over the previous 3 months. She also described intermittent frontal and occipital headaches, polydipsia, polyuria, and nocturia for 7 months. Laboratory evaluation confirmed the diagnosis of diabetes insipidus (DI) with a normal blood glucose level $(87 \mathrm{mg} / \mathrm{dl})$ and urine osmolality of $111 \mathrm{mOsm} / \mathrm{kg}$. The patient required oral desmopressin $(0.1 \mathrm{mg})$ for management. The laboratory tests also showed a mildly elevated prolactin level $(37.8$ $\mathrm{ng} / \mathrm{ml}$ ), but no evidence of other pituitary dysfunction. Her medical history was pertinent only for dyslipidemia.

On examination, the patient was neurologically intact

ABBREVIATIONS DI = diabetes insipidus; EEA = endoscopic endonasal approach; GTR = gross-total resection.

SUBMITTED June 24, 2016. ACCEPTED November 17, 2016.

INCLUDE WHEN CITING Published online April 14, 2017; DOI: 10.3171/2016.11.JNS161605. 


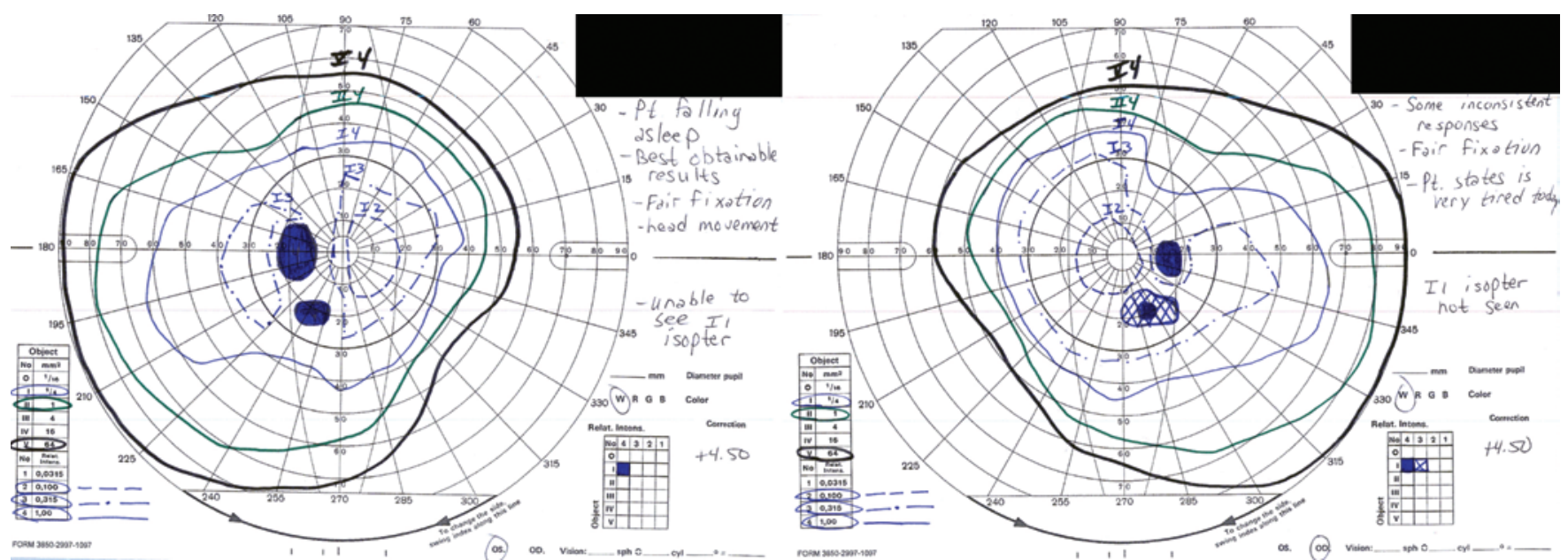

FIG. 1. Goldmann visual field chart of the left eye (left) and right eye (right) revealing bilateral inferior temporal field loss closer to fixation in the left eye and bitemporal relative scotomas. Figure is available in color online only.

except for bilateral inferior temporal field, confirmed with formal Goldmann visual fields (Fig. 1). Her visual acuity was 20/30 in the right eye and 20/40 in the left with correction. Surprisingly, further ophthalmological evaluation also revealed retinal hemorrhages and neovascularization around the terminal superior temporal arcade on the left eye, suggestive of branch retinal vein occlusion.

\section{Neuroimaging Findings}

An MRI study focused on the sella was performed (Fig. 2). The unenhanced mass was causing mild mass effect on the optic chiasm and was extending from the suprasellar to the sellar region; the tumor location correlated with her visual and endocrine symptoms. Due to its intrasellar and suprasellar location and the mixed signal on T1- and T2weighted imaging, a Rathke's cleft cyst and craniopharyngioma were the main differential diagnoses. No diffusionweighted imaging was performed at that time.

\section{Surgical Description}

Due to her worsening visual symptoms and headache, the patient was offered tumor resection. Her case was particularly challenging because a large portion of the cyst extended inferiorly with normal pituitary gland located anteriorly. Although simple fenestration would be sufficient for a Rathke's cleft cyst, the possibility of a solid tumor necessitated a wider exposure for resection. An open approach via a pterional craniotomy and division of the Sylvian fissure would require manipulation of the op- tic nerves and chiasm to access the lesion. An EEA is an ideal choice for this location because it could be modified to provide both suprasellar and infrasellar access.

Using a binarial approach, the sella was completely exposed (Video 1).

VIDEO 1. Clip showing a binarial, expanded EEA to an intrasellar and suprasellar epidermoid cyst. Copyright Joseph D. Chabot.

Published with permission. Click here to view.

Additional bone was removed to expose the clinoidal carotid arteries bilaterally, and a portion of the posterior planum sphenoidale allowing suprasellar exposure. This approach for suprasellar lesions has been well described in the literature. ${ }^{6,9,13}$ The lesion was found situated within the pituitary stalk displacing it anteriorly, and slightly eccentric to the left. The lesion was clearly well defined, solid, with yellowish cyst contents and a shiny "mother of pearl" capsule (Fig. 3). At the level of the pituitary stalk, the content of the cyst was completely evacuated, preserving the stalk as well as all the neurovascular structures.

To access the part of the tumor that was located behind the pituitary gland, an infrasellar interpituitary approach was used, drilling the sella to the level of the clival recess, and displacing normal anterior pituitary gland superiorly. With a $45^{\circ}$ endoscope, a separate dural opening was performed at the sellar floor, and the cleft between the anterior and posterior glands was identified and dissected to reach the remaining epidermoid cyst. The majority of this content was resected and the remainder gently displaced upward into the suprasellar cavity, where it could easily
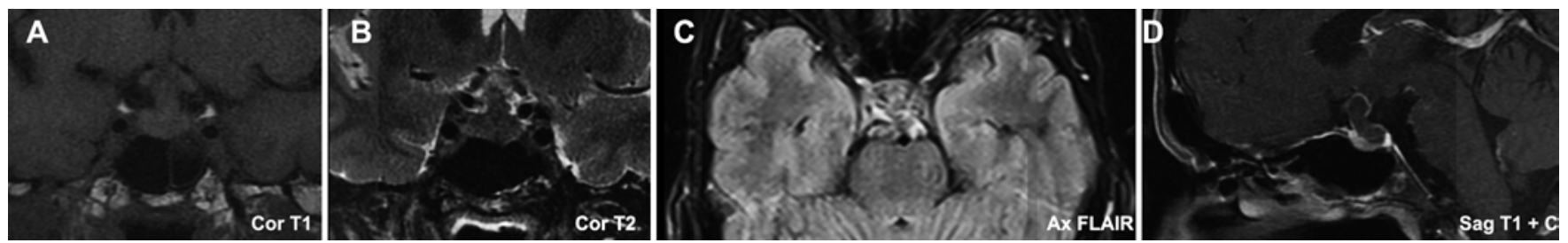

FIG. 2. Coronal T1- (A) and T2-weighted (B) and axial T2-weighted FLAIR (C) MR images showing a mixed-signal lobulated suprasellar mass extending inferiorly into the sella, measuring $1 \times 0.7 \times 1.8 \mathrm{~cm}$. Sagittal Gd-enhanced T1-weighted MR image (D) shows rim enhancement of the lesion without central enhancement. $\mathrm{Ax}=$ axial; $\mathrm{Cor}=$ coronal; $\mathrm{Sag}=$ sagittal; $+\mathrm{C}=$ with contrast. 

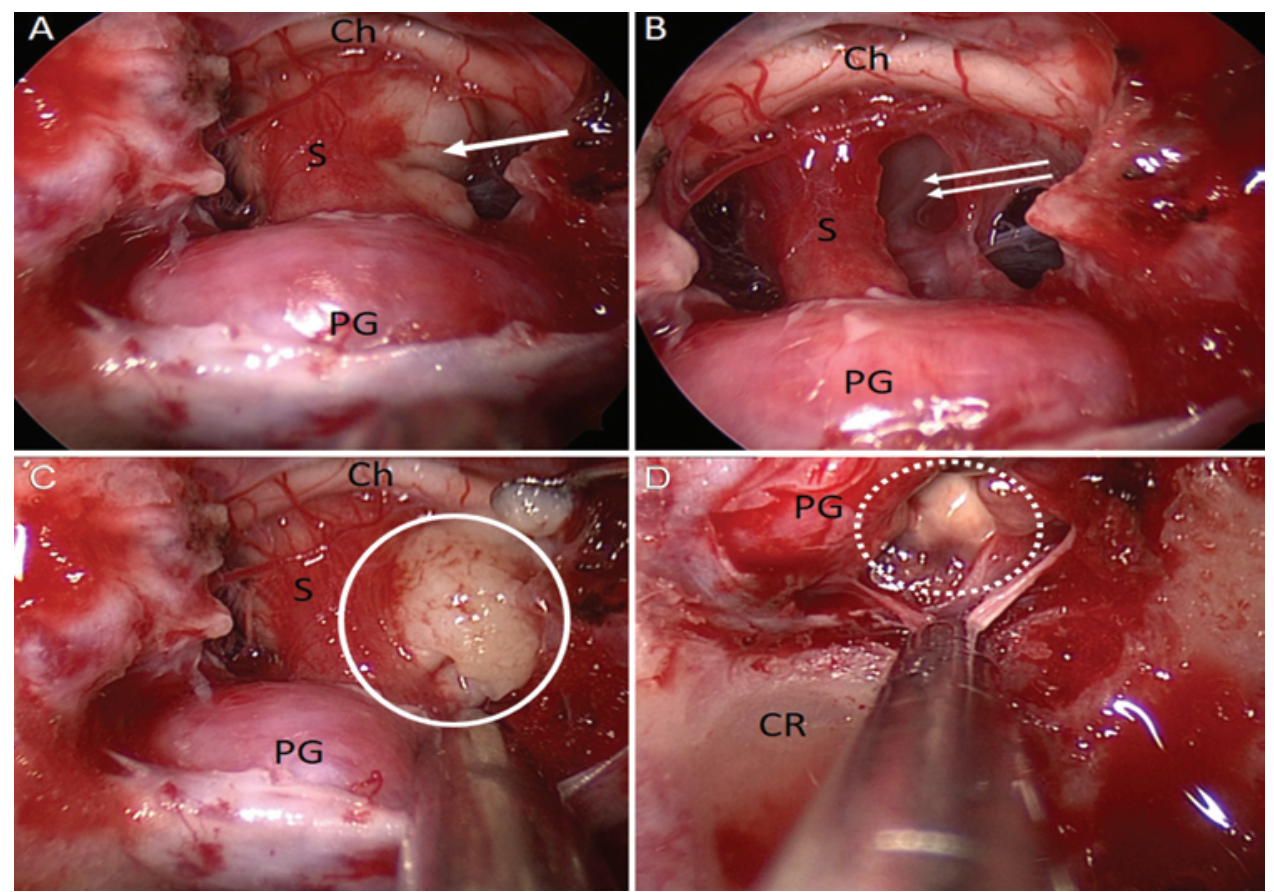

FIG. 3. Endoscopic views of the epidermoid tumor. Following an EEA, views are shown of the pituitary gland (PG), optic chiasm (Ch), clival recess (CR), and pituitary stalk (S). The epidermoid tumor initially appears to be posterior to the pituitary stalk and superior to the pituitary gland (A, arrow), but after resection of the superior portion, the resection cavity shows intact stalk surrounding the tumor (B, arrows). The tumor showed yellowish keratinous appearance consistent with an epidermoid (C, circle). Using a $45^{\circ}$ endoscope from below allows the gland to be displaced superiorly to access the portion of the epidermoid tumor not visible from a superior position (D, dotted circle). Figure is available in color online only.

be removed. Endoscopic inspection revealed gross-total resection (GTR) of the lesion.

Meticulous hemostasis and gentle irrigation was performed to eliminate any potential debris. An inlay layer of collagen dural graft matrix was used to cover the suprasellar space. A nasoseptal flap was placed to cover the skull base defect and reinforced with oxidized cellulose, fibrin glue, and thrombin-soaked collagen sponges.

Both specimens sent to the surgical pathology laboratory revealed keratin debris with no epithelial lining present, compatible with the features of an epidermoid cyst.

\section{Postoperative Course}

Two weeks after surgery, the MR images of the patient demonstrated GTR of the suprasellar mass, with mild thickening of the stalk and some contrast enhancement in the region of the surgical bed (Fig. 4). Postoperatively, the patient experienced no complications and reported subjective improvement of her decreased visual acuity. Her prolactin levels dropped to $13.4 \mathrm{ng} / \mathrm{ml}$, and her DI was well controlled with the same dosage of desmopressin as prior to the surgery. At that time, she did not present with any new endocrinopathies. One year after surgery, she did develop primary hypothyroidism and currently receives 50 mcg of levothyroxine daily.

\section{Discussion}

Epidermoid cysts are congenital lesions resulting from sequestration of embryonic components of the epithelial tissue. 7,8 They are an uncommon pathology, corresponding to $0.2 \%-1.8 \%$ of all primary intracranial tumors, among which $37.3 \%$ are located in the cerebellopontine angle, the most common location, followed by parasellar, middle fossa, diploe, and spinal canal locations. ${ }^{7,8,17,18}$ The initial presentation of these slow-growing cysts is related to its local mass effect, such as hearing impairment, trigeminal neuralgia, facial palsy, diplopia, headaches, seizures and altered mental status. ${ }^{17}$

Whereas long-term survival is generally good in patients with epidermoid tumors, due to their indolent growth pattern, recognition and proper diagnosis is important. Unlike more liquid cysts, which may be evacuated using a less extensive approach, maximal removal of epidermoid tumors requires adequate exposure to allow capsular resection when possible. Although relief of mass effect and debulking is usually sufficient for management of epidermoid tumors, capsular resection decreases regrowth and malignant transformation - a rare phenomenon related to a subtotal excision of the cystic wall and an inflammatory response to recurrent cystic rupture or foreign body reaction - and also prevents recurrences, which were reported in $4.5 \%$ in a group of patients with $79.5 \%$ total or subtotal resection and a median follow-up duration of 8 years. This becomes a significant factor mainly in those patients whose original surgery was performed in younger ages because it tends to reoccur after many years or decades. $7,11,17-19$

A MEDLINE/PubMed search was performed using the following key words: intrasellar AND epidermoid, su- 

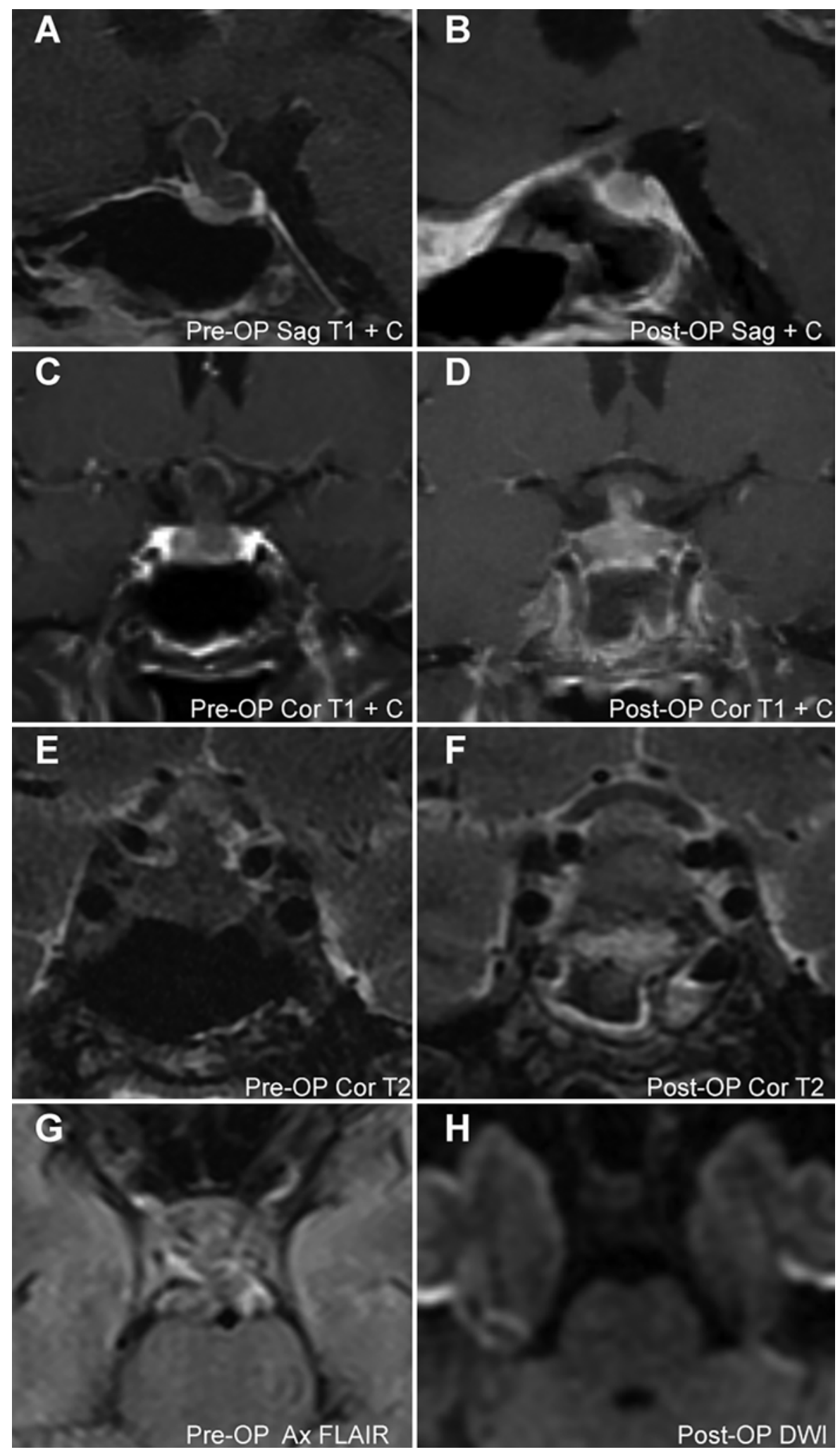

FIG. 4. Comparison between pre- and postoperative images 11 days after surgery. Preoperative sagittal Gd-enhanced T1weighted MRI (A), postoperative sagittal Gd-enhanced T1-weighted MRI (B), preoperative coronal Gd-enhanced T1-weighted MRI (C), postoperative coronal Gd-enhanced T1-weighted MRI (D), preoperative coronal T2-weighted MRI (E), postoperative coronal T2-weighted MRI (F), preoperative axial FLAIR (G), and postoperative diffusion-weighted MRI (H) show no residual disease and extensive enhancement due to postoperative changes. 


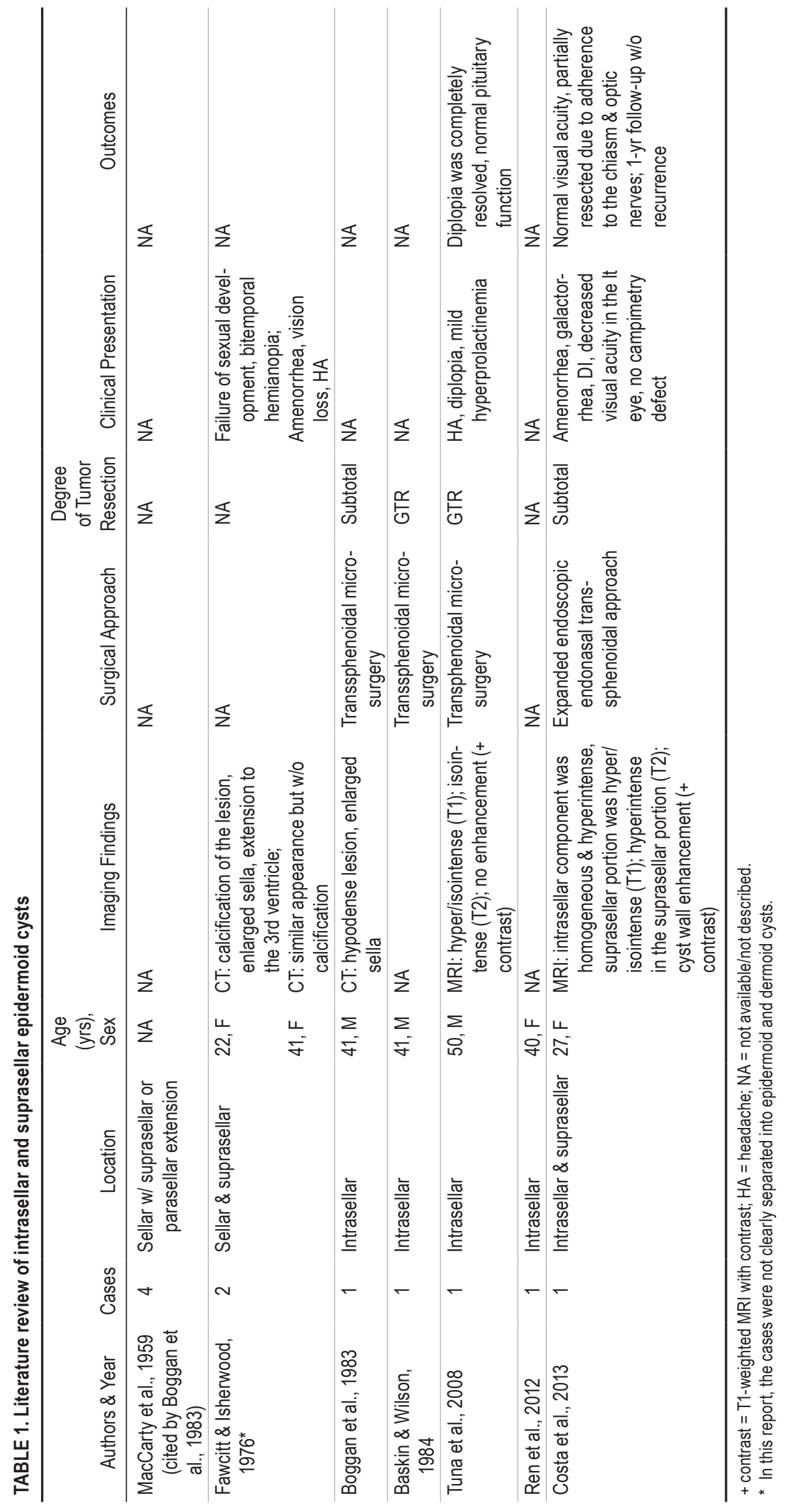


prasellar AND epidermoid, or intracranial AND epidermoid. Five hundred eight reports were identified. A review of these articles and citations identified 11 pertinent cases. Papers in languages other than English, tumors not in an intrasellar or suprasellar location, and other pathologies were excluded. A summary of these cases is presented in Table $1 ., 1,2,4,5,12,18,21$ Of those cases, only 1 located in the pituitary stalk ${ }^{4}$ underwent an endoscopic endonasal transsphenoidal approach to the suprasellar region, without achieving complete resection due to its adherence to the optic chiasm and optic nerves. This is the first case of an epidermoid cyst of the pituitary stalk with successful complete removal via a combined suprasellar and infrasellar interpituitary EEA.

The infrasellar component of this approach was previously described by Paluzzi et al. ${ }^{15}$ to access a Rathke's cleft cyst, which consisted of an exposure of the sellar floor at the level of the clival recess to gain access between the anterior and posterior gland with a $45^{\circ}$-angled endoscope. The authors also described a combined suprasellar and infrasellar approach to access a hypothalamic pilocytic astrocytoma located posterior to the neurohypophysis, but they did not enter between the lobes of the pituitary gland as described in this paper.

Similarly, Silva et al. ${ }^{20}$ described the "above and below" endoscopic endonasal transsphenoidal approach using anatomical specimens and 2 illustrative cases. In contrast to the case presented here, the "above and below" approach described by Silva et al. involves an extensive clival resection and posterior clinoidectomy to access the retrosellar retroinfundibular area and interpeduncular cistern. Among their reported cases, a near-total resection was achieved in an epidermoid cyst extending from the base of the pons up to the retroinfundibular region.

One of the factors confusing the initial diagnosis of this tumor was its atypical presentation on MRI, making it difficult to distinguish from a Rathke's cleft cyst or other cystic sellar lesion. In $94.4 \%$ of the cases, epidermoid cysts present with homogeneous long $\mathrm{T} 1$ and $\mathrm{T} 2$ signals, but they can also present as hypointense on T1-weighted imaging and hyperintense on T2-weighted imaging. Mixed signal in both sequences is considered atypical in the absence of hemorrhage, which is exceedingly rare in epidermoid cysts. $3,7,14,17,18,21$

The rim enhancement reported in this case is also considered atypical for epidermoid cysts, but this appearance could be explained by the enhancement of the stalk displaced around the tumor or due to the chemical inflammation secondary to the leakage of irritating cyst contents. ${ }^{4,10,18,21}$

To elucidate the diagnosis of this lesion, an MRI study with diffusion-weighted imaging may help to differentiate it from other intracranial tumors. ${ }^{7,17}$ However, this sequence is not part of a standard MRI evaluation of pituitary lesions at our institution, and was not initially performed on this patient. Because the preoperative imaging was inconclusive at determining the diagnosis, an EEA offered the option of expansion depending on the tumor's consistency. A suprasellar extension of a standard sellar approach allows visualization of the optic apparatus and pituitary stalk. If the tumor was viscous and easily suc- tioned, this approach would probably have been sufficient to relieve the patient's symptoms. However, because the tumor was solid, and found intraoperatively to extend between the posterior and anterior portions of the pituitary gland, an infrasellar extension allowed access beneath and behind the anterior gland for more direct removal.

This case is a good example of how a combined suprasellar and infrasellar interpituitary approach allows the surgeon to work simultaneously above and between anterior and posterior lobes of the pituitary gland to obtain a complete resection of intrasellar and suprasellar lesions without manipulation of critical neurovascular structures. This case also demonstrates that epidermoid cysts with an uncommon suprasellar and intrasellar location can be completely removed with good clinical outcomes using a combined suprasellar and infrasellar interpituitary endoscopic endonasal transsphenoidal approach.

\section{References}

1. Baskin DS, Wilson CB: Transsphenoidal treatment of non-neoplastic intrasellar cysts. A report of 38 cases. J Neurosurg 60:8-13, 1984

2. Boggan JE, Davis RL, Zorman G, Wilson CB: Intrasellar epidermoid cyst. Case report. J Neurosurg 58:411-415, 1983

3. Chen CY, Wong JS, Hsieh SC, Chu JS, Chan WP: Intracranial epidermoid cyst with hemorrhage: MR imaging findings. AJNR Am J Neuroradiol 27:427-429, 2006

4. Costa F, Felisati G, Maccari A, Bauer D, Lasio G: Epidermoid cyst of the pituitary stalk: case report and review of the literature. Neurosurg Q 23:108-111, 2013

5. Fawcitt RA, Isherwood I: Radiodiagnosis of intracranial pearly tumours with particular reference to the value of computer tomography. Neuroradiology 11:235-242, 1976

6. Gardner PA, Kassam AB, Snyderman CH, Carrau RL, Mintz AH, Grahovac S, et al: Outcomes following endoscopic, expanded endonasal resection of suprasellar craniopharyngiomas: a case series. J Neurosurg 109:6-16, 2008

7. Iaconetta G, Carvalho GA, Vorkapic P, Samii M: Intracerebral epidermoid tumor: a case report and review of the literature. Surg Neurol 55:218-222, 2001

8. Kaido T, Okazaki A, Kurokawa S, Tsukamoto M: Pathogenesis of intraparenchymal epidermoid cyst in the brain: a case report and review of the literature. Surg Neurol 59:211-216, 2003

9. Kassam AB, Gardner PA, Snyderman CH, Carrau RL, Mintz AH, Prevedello DM: Expanded endonasal approach, a fully endoscopic transnasal approach for the resection of midline suprasellar craniopharyngiomas: a new classification based on the infundibulum. J Neurosurg 108:715-728, 2008

10. Lewis AJ, Cooper PW, Kassel EE, Schwartz ML: Squamous cell carcinoma arising in a suprasellar epidermoid cyst. Case report. J Neurosurg 59:538-541, 1983

11. Lopes M, Capelle L, Duffau H, Kujas M, Sichez JP, Van Effenterre R, et al: [Surgery of intracranial epidermoid cysts. Report of 44 patients and review of the literature.] Neurochirurgie 48:5-13, 2002 (Fr)

12. MacCarty CS, Leavens ME, Love JG, Kernohan JW: Dermoid and epidermoid tumors in the central nervous system of adults. Surg Gynecol Obstet 108:191-198, 1959

13. Madhok R, Prevedello DM, Gardner P, Carrau RL, Snyderman CH, Kassam AB: Endoscopic endonasal resection of Rathke cleft cysts: clinical outcomes and surgical nuances. J Neurosurg 112:1333-1339, 2010

14. Morishita T, Watanabe T, Ohta T, Fukushima M, Katayama $\mathrm{Y}$ : Atypical epidermoid cyst with repetitive hemorrhages 
in the supracallosal region: case report. Neurol Med Chir (Tokyo) 49:492-494, 2009

15. Paluzzi A, Fernandez-Miranda JC, Pinheiro-Neto C, Alcocer-Barradas V, Lopez-Alvarez B, Gardner P, et al: Endoscopic endonasal infrasellar approach to the sellar and suprasellar regions: technical note. Skull Base 21:335-342, 2011

16. Raheja A, Eli IM, Bowers CA, Palmer CA, Couldwell WT: Primary intracranial epidermoid carcinoma with diffuse leptomeningeal carcinomatosis: report of two cases. World Neurosurg 88:692.e9-692.e16, 2016

17. Reddy MP, Jiacheng S, Xunning H, Zhanlong M: Intracranial epidermoid cyst: characteristics, appearance, diagnosis, treatment and prognosis. Sci Lett 3:102-110, 2015

18. Ren X, Lin S, Wang Z, Luo L, Jiang Z, Sui D, et al: Clinical, radiological, and pathological features of 24 atypical intracranial epidermoid cysts. J Neurosurg 116:611-621, 2012

19. Rutherford SA, Leach PA, King AT: Early recurrence of an intracranial epidermoid cyst due to low-grade infection: case report. Skull Base 16:109-116, 2006

20. Silva D, Attia M, Kandasamy J, Alimi M, Anand VK, Schwartz TH: Endoscopic endonasal transsphenoidal "above and below" approach to the retroinfundibular area and interpeduncular cistern-cadaveric study and case illustrations. World Neurosurg 81:374-384, 2014

21. Tuna H, Torun F, Torun ANI, Erdogan A: Intrasellar epidermoid cyst presenting as pituitary apoplexy. J Clin Neurosci 15:1154-1156, 2008

\section{Disclosures}

The authors report no conflict of interest concerning the materials or methods used in this study or the findings specified in this paper.

\section{Author Contributions}

Conception and design: Fernandez-Miranda, Nakassa, Chabot. Acquisition of data: all authors. Analysis and interpretation of data: Nakassa, Chabot. Drafting the article: Fernandez-Miranda, Nakassa, Chabot. Critically revising the article: Fernandez-Miranda, Nakassa, Chabot. Reviewed submitted version of manuscript: Fernandez-Miranda, Nakassa, Chabot. Approved the final version of the manuscript on behalf of all authors: Fernandez-Miranda. Administrative/technical/material support: all authors. Study supervision: Fernandez-Miranda, Chabot.

\section{Supplemental Information Videos}

Video 1. https://vimeo.com/197515781.

\section{Correspondence}

Juan C. Fernandez-Miranda, Department of Neurological Surgery, University of Pittsburgh School of Medicine, 200 Lothrop St., PUH Ste. B-400, Pittsburgh, PA 15213-2582. email: fernandezmirandajc@upmc.edu. 